Session 3565

\title{
Advanced Mathematics Preparation for Graduate School of Undergraduate Science and Engineering Students
}

\author{
Kenneth E. Siegenthaler \\ Department of Astronautics \\ United States Air Force Academy
}

\begin{abstract}
The difficulty of inspiring spring-semester senior science and engineering students to take another elective advanced mathematics course is well known. Mathematical Physics taught from a text such as Mathematical Methods for Physicists by George B. Arfken and Hans J. Weber has a particularly bad reputation among undergraduates. But any graduate science or engineering student, who realizes the value of advanced mathematics courses, eventually will include this great mathematics book on their shelf as one of their most used reference books. The trick is to make the course interesting and "enjoyable" enough that students look forward to class, without sacrificing the proper challenges for the student to achieve a proper level of mathematical expertise as preparation for graduate school courses. This paper discusses how to use a combination of:

1.) Textbooks,

2.) Special projects,

3.) Personal interest in the students, and

4.) Relating the material in the course to real world situations,

to reach that goal. These techniques have resulted in positive student critiques, including one evaluation which the author has framed and is on his wall to be reread when he has a bad day.
\end{abstract}

\section{Introduction}

Mathematics is the basis for all science and engineering. A common motto has always been, "If you have room for another course in graduate school, you can never go wrong by taking another math course." The pillars of science in the early 1900's, Einstein, Heisenburg, Planck, Schrodinger, etc., were all superb applied mathematicians. Einstein was obviously a very good pure mathematician as well. The more mathematics a 
scientist or engineer has mastered, along with an engineering attitude of making things work, the versatile the scientist or engineer.

Mathematics 470, Mathematical Physics, is a course taught at the United States Air Force Academy intended for students who will pursue graduate studies in physics and applied mathematics. This course is taught on demand as a spring semester course intended for first classmen (seniors), and second classmen (juniors), who intend to go to graduate school. Various instructors, from the Mathematical Sciences Department or Physics Department, have taught this course over the last 20-plus years. The class is usually small, four to ten students, and taught an average of every other year.

\section{Philosophy}

The overall purpose of this course has been to prepare the students mathematically for graduate courses in physics and applied mathematics. One of the main objectives was to raise mathematical knowledge and comfort level to the graduate level of Arfken[1]. Since some of the students will have Air Force assignments before being sent to graduate school, it is important that they have a reference that will get them up to speed rapidly when necessary to refresh their mathematical background.

Class notes tend to get lost and minds tend to atrophy. Therefore, all examinations were open-book, but not open-notes. On those exams, students were allowed to use their textbooks and anything they have written in them, but not separate notes. This encouraged students to annotate their textbooks with all kinds of hints and other aids to understanding and applying the material in the text. They were also allowed to have worked-out examples of particularly important problems on blank pages in the text. This concept encouraged students to spend more time in the text. It also motivated students to keep their textbooks as references for graduate school. The importance of building a personal professional library was continually emphasized during the course.

The student composition of this class included students majoring in mathematics, physics, astronautics, and electrical engineering. Some students were double majors.

One student was a double major in astronautics and mathematics with a minor in Russian.

\section{Text Selection}

The texts used in the past have oscillated between Mathematical Methods for Physicists by George B. Arfken and Hans J. Weber and Mathematical Methods in the Physical Sciences by Mary L. Boas[2]. Arfken is wider in scope and more theoretical. Boas is limited in the material covered, but is much more understandable for undergraduate students. In the past, when Arfken was used the students have done poorly as a group and have complained that the book was extremely difficult to understand. When Boas has been used, the instructors have commented that they had to extensively supplement the material to bring the course up to the "proper" level. After reviewing these comments by cadets and instructors from past courses and reviewing Arfken and Boas, it was decided to use both texts for the course. The reasoning was that Arfken is at the level required as a mathematical reference in graduate studies in physics and applied

"Proceedings of the 2004 American Society for Engineering Education Annual Conference \& Exposition Copyright @2004, American Society of Engineering Education" 
mathematics. Arfken also has a much broader coverage of applied mathematical subjects employed in graduate courses. There is no doubt that Arfken is the type of mathematical reference book graduate students or practicing researchers would want on their shelves. It is important that the student be comfortable with Arfken. Therefore the philosophy was to use Boas to introduce a new section, then ease the students into Arfken where the same material was covered at graduate level.

\section{Course Content}

This course could easily be a four semester course in order to cover just a portion of the applied mathematical material used in graduate physics and applied mathematics courses. The decision was made to cover areas that other USAFA math courses did not cover or did not cover in sufficient detail,--the idea being that these areas supplement and complement the mathematical program as a whole. The areas covered were series solutions of differential equations, complex variables, calculus of variations, partial differential equations and Green's functions.

An interesting quick exercise is to pick an area of science or engineering and discuss the mathematical tools used and how they vary within a field of study. For example, in Electrical Engineering, it makes a difference if you are a waves person, or a communications person, or computer engineer, or------.. Let's consider some of the mathematical tools used and types of problems involved.

\section{Waveguides and Lasers:}

Partial Differential Equations, Boundary Value Problems, Fourier Series, Bessel Functions, Gaussian, Gaussian-Hermite, Gaussian-Laguerre, Linear Algebra, Lorentzian, Math of Quantum Theory, Math of Binary and Fresnel Optics, and Complex Variables[3].

\section{Control Theory:}

Nyquist Criterion, Bode Plots, Laplace Transforms, Fourier Transforms, Frequency Domain, Time Domain, Complex Variables, State Space, Linear Systems, Non-Linear Systems, and Linear Algebra[4].

\section{Computer Engineer:}

Boolean Algebra, Linear Algebra, Binary Math, Octal Math, Hexadecimal Math, Gray Code, and Complex Variables[5].

\section{Communication Therory:}

Probability, Statistics, Bayes Theorum, Complex Variables, Boolian Algebra, Partial Differential Equations, Frequency Domain, Time Domain, Binary Math, Octal Math,

"Proceedings of the 2004 American Society for Engineering Education Annual Conference \& Exposition Copyright @2004, American Society of Engineering Education" 
Hexadecimal Math, Random Variables, Gaussian Math, Fourier Tansforms, Linear Algebra, Logic, Linear Systems, Bessel Functions, Decision Theory, Discrete Theory, Sampling Theory, Laplace Transforms, and Fourier Math[6,7].

All of that is in addition to the rudimentary math used everyday. The study of mathematics is probably a life's work. The Dean at the Colorado School of Mines has said he expects the average graduate to have seven careers in their lifetime. NOT seven jobs with different companies, seven different careers. Therefore, the emphasis at the Colorado School of Mines is on a very solid foundation in mathematics, physics, chemistry, and good engineering principles. With this foundation students will be able to adapt to wherever the technology leads them. Mathematics is the common glue among those areas. The better one knows mathematics, the better one does physics and chemistry, and the better one applies good engineering principles. We need better sales people to encourage students to take more mathematics.

As a part of the special projects assignments in Math 470, each student taught a lesson on a subject using mathematics related to the course material. An electrical engineering major presented a class on the use of advanced mathematical techniques in communications theory to improve the data download from Global Positioning Satellites for extremely accurate time keeping in the aviation community. A physics major presented a class on gravitational theories connected to relativity. A student who was a double major in astronautical engineering and mathematics with a minor in Russian gave a class on the analysis of the accuracy of experimental data. All of the other lessons were equally excellent in both the level of the mathematical theory and the applicability to the philosophy of our course.

The author has to admit that about five minutes of each class period was spent in talking about Air Force related subjects. The author had 6,300 hours of military aircraft navigation flight time back before GPS and an officer auditing the class had over 2000 flight hours in U-2 aircraft. With alert students the instructor can establish a professional common bond, then the student will want to do well in the course. It makes a difference if the student knows the instructor really cares about the student's future career.

\section{Student Response}

Student responses to the course are documented in Appendices B and C. The written evaluation in Appendix B is particularly encouraging. Appendix C shows the results of compulsory critiques that all cadets fill out at the end of a course. All 23 categories scored extremely high regardless of comparisons with all courses taught in the Mathematics Department, or with all the courses in the Basic Sciences Division, or with all of the courses taught at the Air Force Academy.

The final measure of success in any educational process is the performance of the student in "real" life. Every instructor's dream is to have students excel. At least two students from this class who are doing very well feel this class was very helpful. One student, now at MIT working on his M.S. in Astronautical Engineering, has commented on how

"Proceedings of the 2004 American Society for Engineering Education Annual Conference \& Exposition Copyright @2004, American Society of Engineering Education" 
often he has used the mathematics studied in Math 470. The other member of this class is the Program Manager of a multi-million dollar research and development Air Force program In addition he is in a M.S. program in Operations Engineering/Finance at Boston College and has enrolled in another evening program at Harvard studying government and politics. With a student like that one may ask the question, "Who was teaching whom?"

\section{Conclusions}

Because of all the additional pressures on cadets in their spring semester before graduation, this course had a reputation as a course to avoid if possible. When the instructor demanded high-level performance from Arfken, the cadets hated it. When working with Boas the instructors felt the students were not as well prepared for graduate courses.

The combination of using both Mathematical Methods for Physicists and Mathematical Methods in the Physical Sciences as textbooks in the course, and open book examinations, resulted in an excellent course from both the student's and instructor's point of view. At the completion of the course, the instructor felt all of the students were well prepared for graduate school. Student reactions to the course were encouraging. One student evaluation stated, "Now that I have completed all my finals, and consequently my education at the United States Air Force Academy, I can honestly look back and reflect upon my entire academic experience. Your Math 470 class was absolutely the best class I have taken." This quote was by an electrical engineering major. Another quote, "I actually looked forward to attending class on every lesson! On several occasions, I even called home to tell my parents about the math I was learning." Not the usual comment that a Mathematics Department receives from a cadet on an advanced mathematics course. The complete evaluation in Appendix B makes great reading when the author is having a bad day.

\section{Acknowledgements}

The author would like to acknowledge the contributions and advice of Lt Cols Keith Bergeron and Peter Szyjka during the course. If you enjoyed reading this paper, credit our editors, Dr. Fred Kiley and Ms. Lynnette Kaffine.

\section{Bibliography}

1. Arfken, George B., and Hans J. Weber, Mathematical Methods for Physicists, $5^{\text {th }}$ ed., Harcourt Academy Press, New York, 2001.

2. Boas, Mary L., Mathematical Methods in the Physical Sciences, $2^{\text {nd }}$ ed., John Wiley \& Sons, New York, 1983.

3. Plonsey, Robert, and Robert E. Collin, Principles and Applications of Electromagnetic Fields, McGrawHill, New York, 1961.

4. Shinners, Stanley M., Modern Control System Theory and Application, $2^{\text {nd }}$ ed., Addison-Wesley, Reading, MA, 1978.

"Proceedings of the 2004 American Society for Engineering Education Annual Conference \& Exposition 
5. Daniels, Jerry D., Digital Design from Zero to One, John Wiley \& Sons, New York, 1996.

6. Peebles, Peyton Z., Jr., Probability, Random Variables, and Random Signal Principles, McGraw-Hill, New York, 1987.

7. Sklar, Bernard, Digital Communications and Applications, Prentice Hall, Englewood Cliffs, NJ, 1088.

\section{Biography}

KENNETH E. SIEGENTHALER is an Associate Professor of Astronautics at the U.S. Air Force Academy. Dr. Siegenthaler has a B.S in the Arts \& Sciences from the U.S. Military Academy, a B.S. in Physics from the University of Utah, and a M.S. and a Ph.D. in Engineering Physics from the Air Force Institute of Technology. He is a registered Professional Engineer in the state of Colorado. 


\section{Appendix A}

MATH 470, SPRING 2002

Mathematical Physics

\begin{tabular}{|c|c|c|c|}
\hline$\underline{\mathrm{L}}$ & $\begin{array}{l}\text { READING } \\
B=\text { Boas } \\
\text { A=Arfken }\end{array}$ & TOPIC & $D U E$ \\
\hline & & Series & \\
\hline 1 & $\begin{array}{l}\text { B: } 1.1-1.4 \\
\text { A: } 5.1\end{array}$ & $\begin{array}{l}\text { Geometric Series, Definitions, } \\
\text { Applications, Series Convergence }\end{array}$ & \\
\hline 2 & $\begin{array}{l}\text { B: } 1.5-1.6 \\
\text { A: } 5.2\end{array}$ & Tests for Convergence & \\
\hline 3 & $\begin{array}{l}\text { B: } 1.7-1.10 \\
\text { A: } 5.3\end{array}$ & $\begin{array}{l}\text { Alternating Series, Conditional } \\
\text { Convergence, Power }\end{array}$ & \\
\hline 4 & $\begin{array}{l}\text { B: } 1.11 \\
\text { A: } 5.4-5.6\end{array}$ & Theorems about Power Series & Prob Set \#1 \\
\hline 5 & $\begin{array}{l}\text { B: } 1.12,4.2 \\
\text { A: } 5.7\end{array}$ & $\begin{array}{l}\text { Expanding Functions in Power } \\
\text { Series, Power Series in } 2 \text { Variables }\end{array}$ & \\
\hline 6 & B: 1.13 & $\begin{array}{l}\text { Techniques for Obtaining Power } \\
\text { Series }\end{array}$ & \\
\hline 7 & B: $1.14-1.16$ & Some Uses of Power Series & Prob Set \#2 \\
\hline \multirow[t]{2}{*}{8} & $\begin{array}{l}\text { Graded Review } \\
1\end{array}$ & GR \#1 & GR \#1 \\
\hline & & Complex Variables & \\
\hline 9 & $\begin{array}{l}\text { B: } 14.1 \\
\text { A: } 6.1\end{array}$ & Introduction to Complex Variables & \\
\hline 10 & $\begin{array}{l}\text { B: } 14.2 \\
\text { A: } 6.2\end{array}$ & Analytic Functions & \\
\hline 11 & $\begin{array}{l}\text { B: } 14.3 \\
\text { A: } 6.3,6.4\end{array}$ & Complex Integrals & Prob Set \#3 \\
\hline 12 & $\begin{array}{l}\text { B: } 14.4 \\
\text { A: } 6.5\end{array}$ & Laurent Series & \\
\hline 13 & $\begin{array}{l}\text { B: } 14.5 \\
\text { A: } 7.1,7.2\end{array}$ & The Residue Theorem & \\
\hline 14 & B: 14.6 & Methods of Finding Residues & \\
\hline 15 & B: 14.7 & $\begin{array}{l}\text { Evaluation of Integrals by Use of the } \\
\text { Residue Theorem }\end{array}$ & Prob Set \#4 \\
\hline 16 & Review & Review of Block 2 & \\
\hline 17 & $\begin{array}{l}\text { Graded Review } \\
2\end{array}$ & GR \#2 & GR \#2 \\
\hline
\end{tabular}




\section{Series Solutions of Differential Equations}

18 B: 12.1-12.3 A: Introduction, Legendre's Equation, 12.1, 12.2, 12.5 Leibniz's Rule

19 B: $12.4-12.5$

Rodriques' Formula, Generating

A: 12.4

20 B: 12.6

A: 12.3

Functions for Legendre Polynomials

Complete Sets of Orthogonal

$21 \quad$ B: $12.7-12.8$

Functions

Ortho-Normality of the Legendre

Polynomials

22 B: 12.9-12.10

Legendre Series and Associated

Prob Set \#5

23 B: 12.11

Legendre Polynomials

Method of Frobenius (Part I)

A: 8.5

24 B: 12.12

A: 8.6

25 B: 12.13

A: 11.1

26 B: 12.14-12.17

Method of Frobenius (Part II),

Bessel's Equation (Part I)

Bessel's Equation (Part II), $2^{\text {nd }}$

Solution to Bessel's Equation

Tables of Bessel Functions,

Recursion Relations, Other Bessel

Functions

27 B: 12.18

28 B: 12.19-12.20

The Lengthening Pendulum

Prob Set \#6

Orthogonality of Bessel Functions,

A: 11.2

Approximations for Bessel Functions

29 B: $12.21-12.22$

Series Solutions to Differential

Equations and Review

30 Graded Review

GR \#3

GR \#3 3

\section{Calculus of Variations}

31 B: 9.1-9.2 Introduction and Euler's Equation

A: 17.1

32 B: 9.3
A: 17.2

33 B: 9.4

Using the Euler Equation

33 B: 9.4

The Brachistochrone Problem;

Prob Set \#7

34 B: 9.5

\section{Cycloids}

A: $17.3,17.7$

35 B: 9.6

36 B: 9.7

Lagrange's Equations

37 Review

Isoperimetric Problems

38 Graded Review 4

Variational Notation

Review of Block 4

Prob Set \#8

GR \#4

GR \#4 


\section{Partial Differential Equations and Green Functions}

39 B: 13.5-13.6 A: Steady-State Temperature in a

$8.1-8.3$

Cylinder, Vibrating Circular

Membrane

40 B: 13.7

41 B: 15.7

1.15

Steady-State Temperature in a Sphere

$42 \quad$ B: 15.8

8.7

A: Dirac Delta Function

A: Green Functions 


\section{Appendix B}

\section{Math 470 Student Evaluation}

From: Sousa Kevin C1C CS36

Sent: Friday, May 17, 2002 12:07 PM

To: Siegenthaler Kenneth Dr USAFA/DFMS

Subject: Thank You

Dr. Siegenthaler,

I felt our brief exchange after the final did not adequately emphasize how much I enjoyed your Math 470 class. Now that I have completed all my finals, and consequently my education at the United States Air Force Academy, I can honestly look back and reflect upon my entire academic experience. Your Math 470 class was absolutely the best class I have taken. I am sure this is entirely due to your abilities as a professor. As an electrical engineer I have taken many technically challenging classes and often found professors merely presented the material. This has no more value then picking up the text myself and reading through it. I believe the greatest professors are those who go beyond copying an equation to the board and are those who actually teach! From a few opportunities I have had to present before a class, I realize that this is a far more complicated exchange which requires a great deal of extra effort and an ability to relate. You have mastered this to the point where I actually looked forward to attending class on every lesson! On several occasions, I even called home to tell my parents about the math I was learning from such a distinguished and inspiring individual. I have never written a letter of this sort. Please accept the sincerity of its intentions.

Best wishes for the future.

C1C Kevin Sousa 


\section{Appendix C}

\section{Math 470 Student Course Critiques}
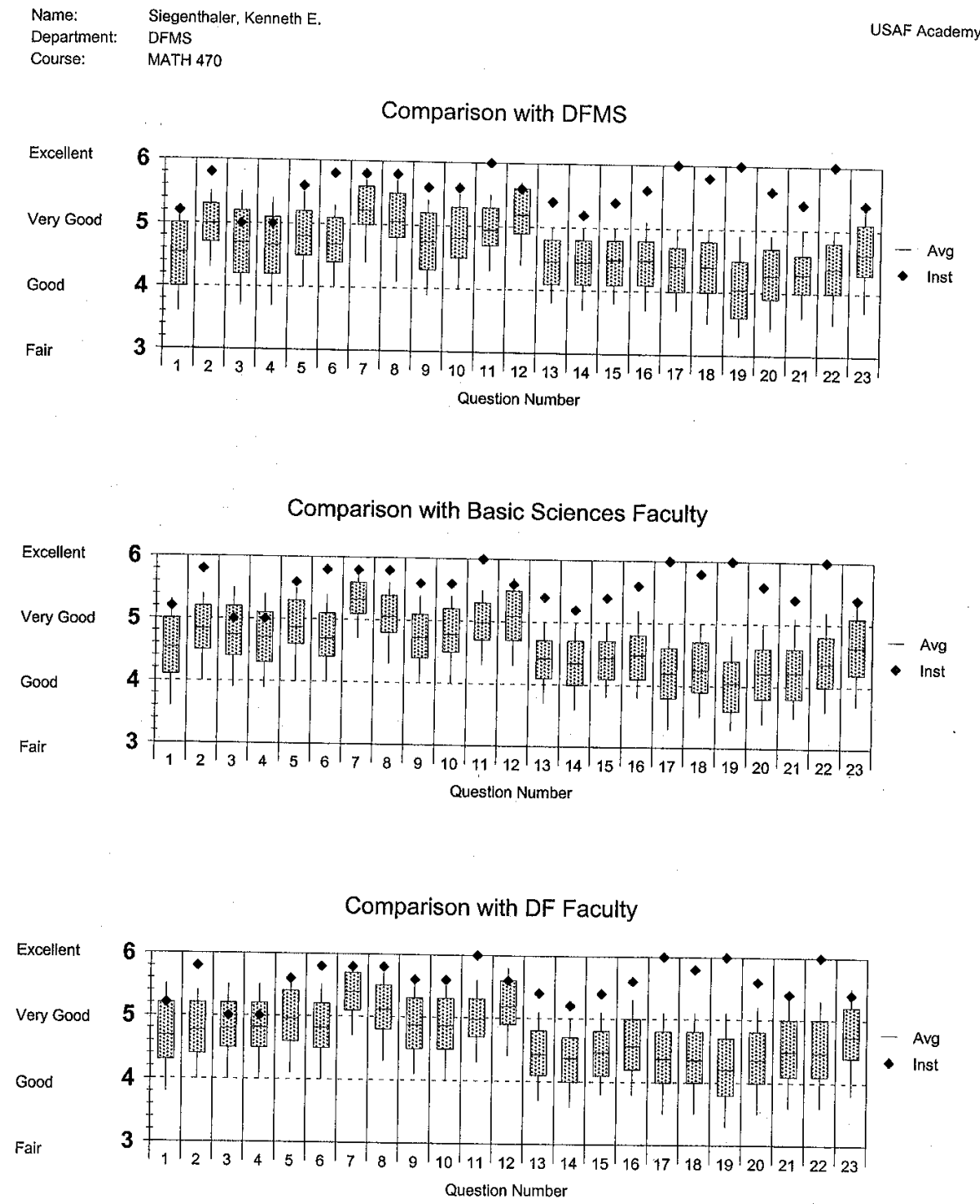

Questions 1-12: Feedback to Instructor 


\section{APPENDIX C (Continued) \\ KEY AND RESULTS OF THE STUDENT COURSE CRITIQUES FOR MATHEMATICS 470 MATHEMATICAL PHYSICS}

\section{KEY TO QUESTIONS ASKED ON THE CRITIQUE FORMS}

\section{SECTION FOR DIAGNOSTIC FEEDBACK TO THE INSTRUCTOR}

1. INSTRUCTOR ABILITY TO STIMULATE MY INTEREST WAS?

2. QUANLITY AND TIMELINESS OF FEEDBACK ON GRADED WORK WAS?

3. INSTRUCTOR'S ABILITY TO PROVIDE CLEAR, WELL ORGANIZED INSTRUCTION WAS?

4. INSTRUCTOR'S ABILITY TO PRESENT ALTERNATIVE EXPLAINATION WHEN NEEDED?

5. INSTRUCTOR'S USE OF EXAMPLES AND ILLUSTRATIONS WAS?

6. VALUE OF QUESTIONS AND PROBLEMS RAISED BY INSTRUCTOR WAS?

7. INSTRUCTOR' KNOWLEDG OF THE COURSE MATERIAL WAS?

8. AS A MILITARY ROLE MODEL OR CIVILIAN PROFESSIONAL ROLE MODEL, MY INSTRUCTOR WAS?

9. ENCOURAGEMENT GIVEN STUDENTS TO EXPRESS THEMSELVES AND PARTICIPATE WAS?

10. INSTRUCTOR'S CONCERN FOR MY LEARNING WAS?

11. AVAILABILITY OF EXTRA HELP WHEN NEEDED WAS?

12. INSTRUCTOR'S ENTHUSIASM WAS?

\section{INFORMATION ABOUT THE CLASS}

13. COURSE ORGANIZATION WAS?

14. CLARITY OF COURSE OBJECTIVES AND REQUIREMENS WAS?

15. THE DEGREE TO WHICH THE COURSE MET ITS STATED OBJECTIVE WAS?

16. INTELLECTUAL CHALLENGE AND ENCOURAGEMENT OF INDEPENDENT THOUGHT WAS?

17. REASONABLENESS (DIFFICULTY AND AMOUNT) OF ASSIGNED WORK WAS?

18. EVALUATIVE AND GRADING TECHNIQUES (TESTS, PAPERS, PROJECTS, ETC.) WERE?

19. QUALITY AND USEFULNESS OF COURSE TEST(s) WERE?

\section{GENERAL EVALUATION}

20. THE COURSE AS A WHOLE WAS?

21 RELEVANCE AND USEFULNESS OF COURSE CONTENT WERE?

22. AMOUNT YOU LEARNED IN THE CLASS WAS?

23. THE INSTRUCTOR'S EFFECTIVENESS IN FACILITATING MY LEARNING IN THE COURSE WAS? 